\title{
Intrafamilial disclosure of risk for hereditary breast and ovarian cancer: points to consider
}

\author{
Lee Black • Kelly A. McClellan • Denise Avard • \\ Bartha Maria Knoppers
}

Received: 31 January 2012 / Accepted: 13 December 2012 / Published online: 29 December 2012

(C) The Author(s) 2012. This article is published with open access at Springerlink.com

\begin{abstract}
The primary goal of breast and ovarian cancer screening is to minimize the cases of advanced disease and therefore its mortality rate. For hereditary breast and ovarian cancer, one method to reach this goal is to disseminate genetic risk information among family members. However, experience tells us that this information does not always reach family members in a timely manner, if at all. There are many moving parts to a decision to disclose genetic risk information within a family, and the lack of detail and cohesion in current guidelines do a disservice to hereditary breast cancer prevention. Utilizing legal, medical, and policy databases for literature, case law and policy documents relating to communication of genetic test results within families, as well as a consultative process with representative stakeholders, a points to consider has been developed to address a number of issues that might impact the ability and willingness of patients to inform family members of genetic risk. These include: what is "genetic information"; who is the "family"; why should patients inform their family members; and how should health professionals be involved in this process? This represents only an initial step towards fostering better communication within families. Additional research is needed to determine the best methods for encouraging this communication and motivations for disclosing or not and to promote the development of a solution, considering the complexity of human relationships and the probabilistic nature of genetic information.
\end{abstract}

Keywords Family · Communication - Genetic information · Breast cancer $\cdot$ Intrafamilial

L. Black $(\bowtie) \cdot$ K. A. McClellan · D. Avard • B. M. Knoppers

Centre of Genomics and Policy, McGill University,

740 Dr. Penfield Ave., Suite 5200,

Montreal, QC, Canada H3A 0G1

e-mail: lee.black@mcgill.ca

\section{Introduction}

Stemming from the increased availability in genetic sequencing technologies, a new emphasis has emerged on the intrafamilial communication of a patient's genetic information back to their family members (Wiseman et al. 2010). With the growth of genetic medicine and genetic testing, "it is reasonable to assume that growing numbers of relatives would wish to be informed of their risks" (Lucassen and Parker 2010). For diseases like hereditary breast and ovarian cancer, communicating a patient's cancer diagnosis or genetic risk profile back to their family provides family members the opportunity to take advantage of additional testing, screening, and other cancer risk-reducing interventions that become available to those with a family history that suggests higher risk (Carroll et al. 2008).

Despite the importance of intrafamilial communication, hurdles have emerged to its widespread promotion by health care professionals and completion by patients. Messages surrounding intrafamilial communication emphasize the choice patients have in choosing whether to disclose results to their relatives, potentially decreasing the urgency of the disclosure (Forrest et al. 2007). In addition, research has shown that intrafamilial communication is a complex and delicate task. It requires patients to first absorb complicated information from health care professionals about their own health (Meiser et al. 2012; MacDonald et al. 2010) and then communicate this delicate information to family members with diverse educational and generational backgrounds while navigating family dynamics (Peters et al. 2011; Foster et al. 2004; Claes et al. 2003; Hallowell et al. 2005). Further, for some patients, the act of considering whether to disclose information to their family members will compete with the sometimes more time-sensitive need to consider their own health care, as such information often becomes available following a diagnosis of cancer or high-risk status (Meiser et al. 2012). 
For those patients willing to disclose, the role that health care professionals play in encouraging and supporting patients' efforts to communicate with family members is unclear. Guidelines and policy for health care professionals with respect to counseling patients for intrafamilial communication are scant (Forrest et al. 2007; Nycum et al. 2009a). In response, diverse groups of health care professionals have called for research and guidance in this area (Kissane et al. 2012; MacDonald et al. 2010; Pelletier and Dorval 2004). The importance of a more cohesive and detailed strategy for intrafamilial communication is demonstrated by the proposal of legislation to allow health care professionals to inform their patients' relatives of their risk for genetic disease without consent (Patty 2012) and litigation over a medical doctor's professional responsibility to inform relatives of their patient of the risks of inherited disease (Watters $\mathrm{v}$. White 2012). These fill the vacuum with legal solutions that might not be appropriate or effective.

In our previous research, we identified major themes underlying the development of policy with respect to intrafamilial communication, namely: (1) Who is a family member?; (2) What types of information should be disclosed?; (3) What is the expectation for patients with respect to intrafamilial communication?; and (4) What is the role for health professionals in any system of intrafamilial disclosure? (Nycum et al. 2009a). For this paper, we narrow the focus to hereditary breast and ovarian cancer primarily due to its prevalence, especially in the literature, in much of the discussion surrounding the disclosure of risk information to family (intrafamilial or otherwise). In an effort to guide policy development for health care professionals and encourage intrafamilial communication by patients, we have conducted a review of applicable norms and literature, followed by a consultation with key stakeholders. From this, we suggest the key points to consider underlying the above five themes for policy- and decision-makers to consider when formulating guidance in this area.

\section{Methods}

\section{Document collection}

The currently applicable normative frameworks surrounding intrafamilial communication of hereditary breast and ovarian cancer in Canada, France, Australia, USA, and UK were determined by reviewing the following classes of documents: (1) laws and regulations (provincial and federal) currently in force; (2) applicable case law; (3) guidelines and rules adopted by professional associations; (4) directives and guidelines adopted by hospitals and health care providers; and (5) policies adopted by patient advocacy groups.
Relevant laws and regulations in force were identified by searches in official compendia of laws and regulation. Relevant case law was obtained by searching legal electronic databases such as SOQUIJ, QuickLaw, and WestlawCarswell. Relevant legislation examined concerned human rights and freedoms (particularly, privacy and protection of personal information), civil liability in general, duties of health professionals, children's rights, parental rights and duties (family law), state duties towards parents and children in the provision of health care, and the related case law therein.

Guidelines, policies, and recommendations published since 1995 were obtained by conducting a review of HumGen.org (www.humgen.org/int/_ressources/Method_en.pdf, a database of laws and policies related to human genetics), keyword-driven searches of other databases including PubMed and Google, and searches of relevant organizational websites.

Academic literature on intrafamilial communication of hereditary breast and ovarian cancer literature was obtained using internet search engines, specialized databases (e.g., PubMed, Philosophers' Index, Kennedy Institute of Bioethics, and Google Scholar), libraries, and manual searches of relevant publication indexes and publications. All databases and search engines were searched using the following search terms: "famil*" [and] "genetic" or "cancer" [and] "communicat*."

\section{Document analysis}

Two members of the research team (LB and KAM) identified the key points to consider through content analysis of the normative documents and academic literature. Guided by the themes previously identified as underlying intrafamilial obligations to communicate, normative documents were first examined to identify key considerations underlying each theme (Nycum et al. 2009a). To supplement the analysis, alternative regulatory scenarios were obtained by examining the regulatory frameworks in Australia, UK, France, and the USA, while additional considerations were identified through searches of the academic literature. From this analysis, a preliminary draft of the points to consider was assembled.

\section{Consultative process}

Validation of the points to consider was conducted by an iterative two-step consultative process, which took place in spring and autumn of 2010. In the first step, the preliminary draft points to consider was circulated among representative stakeholders purposefully drawn from the following stakeholder groups: nursing, genetic counseling, and patient advocacy communities for hereditary breast and ovarian cancer. Participants were gathered from the Montreal region 
and identified through existing networks. In the round table discussion that took place in Montreal in April 2010, participants were asked to comment on the content of the draft points to consider, identify key priorities, and supplement the points based on experience. The draft points to consider was revised to reflect input gained from the first consultation. In the second step, the revised points to consider was circulated and presented as oral presentations to audiences of researchers and trainees in two separate forums: the Canadian Association of Genetic Counsellors Annual Education Conference, held in Halifax, NS, in October 2010, and the National Conference on Genomics and Public Health, held in Bethesda, Maryland, in December 2010. The points to consider was further modified to reflect feedback obtained from conference participants following each presentation. Revisions were made under the auspices of the Chatham House Rule, as no comments were attributed to any individual or organization.

\section{Results}

Who is part of the genetic family?

Any obligation to disclose genetic information to family members rests upon the determination of who, exactly, is "family." This may seem like a simple question, but the genetic context raises a number of complexities. Should the family be defined exclusively by genetic or blood ties? What degree of blood relation should be required when considering inclusion in the family? Should factors other than biology be taken into consideration when defining the genetic family? For example, should individuals with strong social or legal ties who could have an interest in the information, such as non-biological children, spouses, partners, and in-laws, be included as members of the family when it comes to genetic information?

Definitions of genetic family have been debated among scholars, and both traditional and broad views have been advocated. According to the traditional view - a biologic model-the genetic family is defined primarily by blood ties and traditional legal relationships, such as marriage and reproduction (Laurie 2002): those who have an interest in the information, based on individual health concerns or personal reproductive choices. Thus, the genetic family would be limited to blood relatives and spouses and would exclude adopted children as well as same sex and cohabitating partners or others who may have a need to know the information aside from their own personal health. While on the surface this definition appears unequivocal in identifying who is a genetic family member, it is problematic as there is potentially no limit to the degree of biologic relation that could be included, however far removed. This disregards the practical realities of family dynamics, by asking patients to disclose genetic information to distant blood relatives with whom the patient has little to no preexisting social relationship. It also ignores the interests of non-blood relations. Further, it ignores the contribution that other family members could make in disseminating family history information (Koehly et al. 2009).

In contrast, there is a broad view of the genetic family that accounts for both biological and social interests. According to this biosocial model, in the absence of a biological relationship, a preexisting social relationship could substitute as the defining criteria for identifying a family member (Gilbar 2005). As a consequence, a wide range of relationships would qualify as familial relationships, such as same sex partners. In addition, in the complete absence of a preexisting social relationship, this model could excuse individuals from classification as family members, even if there is a biological relationship. This, for example, would allow for exclusion of a sperm donor from family or distant cousins who have never met. The emphasis on the sociological aspect, however, is not without criticism. One can question the reasoning or fairness of refusing to communicate with close family members in families that are in the midst of breakdown or with whom a patient has never had a personal relationship (assuming the patient knows of the family members and has the means and knowledge to contact them). This disadvantage aside, the flexibility afforded by the biosocial model represents a key advantage, as the model is capable of adapting to the myriad of legal and social relationships found within today's modern family.

Recognizing the unique challenges brought about through knowledge of genetic information, many organizations, including ethics and medical genetics groups and physician and patient advocacy groups, have attempted to acknowledge both the familial and individual nature of genetic information (Forrest et al. 2007). Some European bodies have addressed the definition of the family directly and have adopted either narrow or broad views of the family. For example, an expert subgroup within the European Commission has adopted an approach closely resembling the biologic view by acknowledging that genetic testing is of consequence to blood relatives such as offspring (European Commission: The Independent Expert Group 2004). In contrast, both the French National Consultative Ethics Committee and German Society of Human Genetics have broadened this biologic definition, noting that results of a genetic test are of interest to the extended family, including legal relatives such as spouses (France National Consultative Ethics Committee for Health and Life Sciences (CCNE) 2003; German Society of Human Genetics 1998).

In Canada and the USA, however, the various guidelines examined applied primarily to physician disclosure to family, rather than intrafamilial disclosure. These guidelines do 
not adopt positions defining the genetic family, instead affirming that with regards to genetic information, the privacy considerations of the individual should prevail (Watson and Greene 2001; Canadian Medical Association 1999; American Society of Human Genetics 2000).

While these debates regarding the appropriate definition of the family still persist, some jurisdictions have adopted legislation (generally more authoritative than guidelines) that defines family in relation to genetic information. The USA enacted the Genetic Information Non Discrimination Act (GINA) in 2008, which seeks to prevent the use of genetic information of individuals or their family members as grounds to deny access to health insurance or employment. In defining family, the act identifies relatives up to and including fourth degree relatives (U.S. Bill H.R. 493 Genetic Information Nondiscrimination Act of 2008 (110th Cong.) 2008). Further, the definition also includes eligible dependents, though eligible dependents are limited to married spouses and adopted children (U.S. Bill H.R. 493 Genetic Information Nondiscrimination Act of 2008 (110th Cong.) 2008). By emphasizing blood relatives and traditional legal relationships, the position of USA closely resembles the expanded biologic view of genetic family. The state of Illinois has adopted similar legislation, but also includes any individual related by blood or law to the patient or his or her child or spouse, thus greatly increasing the pool of potential family members (Genetic Information Privacy Act 2009).

Australia adopted guidelines for the use and disclosure of genetic information to patients' genetic relatives, who are defined to include only individuals related by blood (Government of Australia 2009). Furthermore, disclosure is recommended to up to third degree relatives. These guidelines apply to disclosure by private sector health professionals (explicitly excluding public sector professionals/facilities and the government) without the consent of the patient, which might be why the boundaries of genetic relatives are so narrowly defined. In contrast, Australia previously considered legislation (never adopted) that included a broad definition of genetic family. In the Genetic Privacy and Non Discrimination Bill (Government of Australia 1998), which had similar objectives to the US GINA, a family member was defined as being either biological or legal relatives who would have a material interest in the genetic information. However, the relative weight assigned to each factor (biological versus legal relative) in establishing status as a family member was unclear, as was the component of "material interest."

There are a wide variety of definitions of family, ranging from the very narrow and specific to the very broad. However, these definitions are not applied specifically in the context of intrafamilial communication, but rather for the protection of genetic information or communication by health professionals. It would be reasonable, then, to propose that for intrafamilial communication, the family could be considered from a more expansive perspective.

Points to consider: definition of the family

1. The genetic family has been defined to include blood ties, preexisting social relationships, or both.

2. A social relationship can be an important factor in deciding to whom to disclose genetic information. Spouses, adopted children, stepparents, and partners could all have an interest in knowing this information even if it will not affect their personal health, such as for reproductive planning or making health decisions in the event of the patient's or other family member's incapacity.

3. An ideal definition of family would strike an appropriate balance between the biological and the social (marriage, cohabitation, adoption, etc.) when characterizing an obligation to communicate, as well as the purpose of and need for the information, in order to incorporate the varied familial relationships across society.

4. The degree of the relationship should also be a consideration. There is no good rule as to how broad family should be defined (some laws use fourth degree relatives and others third degree), but the more tenuous degree of blood relation the less beneficial the disclosure will be compared to the loss of privacy and confidentiality for the patient.

5. A definition of family should also consider the health interests of the family member, regardless of the closeness of the relationship between the patient and family member or their blood ties. For example, siblings still have a strong interest in the information even if their personal relationship with the patient is poor: the absence of a social relationship in this instance should not be a determining factor for disclosure.

What constitutes genetic information that patients should be encouraged to disclose?

Advances in the genetic sequencing and understanding of cancer have created new categories of information. Hereditary breast and ovarian cancers illustrate the questions raised when determining the kind of information patients should be encouraged to disclose. Is it only information discovered through DNA-based genetic testing from laboratory analyses? Or are histological analyses of tumors that would strongly suggest hereditary cancer included? Is information from breast cancer risk prediction models suggestive of a probability of heritable cancer risk included? Is family history of breast cancer genetic information?

\section{What is "genetic information?"}

The debate over what constitutes genetic information raised in other contexts, such as insurance (O'Neill 1997), echoes the question raised here: what is genetic information for which family members have an interest? Inquiries have traditionally focused on laboratory DNA testing that provides information about heritable gene variants (American Society of Clinical Oncology 2003). However, as technology evolved, other non-DNA-based testing strategies have 
emerged that have the capacity to produce information suggestive of heritable genetic variants for which family members may have an interest. For example, with respect to breast cancer, so-called triple negative breast tumor pathologies are the results of non-DNA-based pathology testing that suggests presence of BRCA1 or BRCA2 mutations (Peshkin et al. 2010; Meyer et al. 2012). Thus, questions are raised as to whether patients should be counseled of the consequences such results may have for their families.

In addition to lab-based genetic testing, other methods have arisen to estimate a patient's risk of carrying a genetic mutation and developing cancer, which might be of importance to family members. A number of genetic risk assessment models, such as BOADICIA, BRCAPRO, the Myriad tables, IBIS, and others (Antoniou et al. 2008; Jacobi et al. 2009), have been developed to incorporate information such as family history of cancer, lifestyle, and the presence of a particular genetic mutation in the family. They are intended to provide a more accurate evaluation of risk than family history alone. Patients are placed in low-, medium-, or highrisk categories that can be used to refer for further testing, as many guidelines recommend genetic testing only if the probability of a mutation is above a certain percentage (Antoniou et al. 2008). The probabilities generated by these models can be considered genetic information since they indicate a potential level of risk for developing cancer or having a genetic mutation and act as gatekeeper for access to subsequent testing and cancer risk-reducing medical interventions (Carroll et al. 2008).

Family history is a further source of genetic information. As genetic knowledge expands, "benign" family histories, long integral to medical care, are acquiring greater significance as scientifically valid sources of medical or genetic information (Guttmacher et al. 2004; Claes et al. 2003). In relation to breast cancer, family history information is required for targeting interventions at high-risk individuals who can most benefit from available preventive strategies (Carroll et al. 2008). Consequently, the diagnosis of breast cancer or the discovery of a genetic mutation in a patient becomes family history information that relatives have an interest in knowing.

\section{Genetic information in current guidance}

There are multiple views in the documents we examined on the breadth of what constitutes genetic information, though there is general agreement that information obtained from clinically accepted laboratory-based genetic tests constitutes genetic information. Some guidelines, however, view this as the only source of genetic information and limit genetic to "inheritable." For example, the United Nations Educational, Scientific, and Cultural Organization (UNESCO) defines human genetic data as "information about heritable characteristics of individuals obtained by analysis of nucleic acids or by other scientific analysis" (UNESCO 2003).

A number of organizations and governments, though, have adopted a broad view of what constitutes genetic information, covering a wider range of information, which includes family history and could be extended to analysis of risk prediction models. In the USA, GINA provides such a definition and includes genetic tests, the genetic tests of family members, and the manifestation of a disease or disorder in family members (U.S. Bill H.R. 493 Genetic Information Nondiscrimination Act of 2008 (110th Cong.) 2008). Other countries that apply a broad definition of genetic information include the UK, where genotype, phenotype, and family information are explicitly included ( $\mathrm{Hu}-$ man Genetics Commission 2002; Royal College of Physicians et al. 2011), and the Council of Europe where:

"the expression 'genetic data' refers to all data, of whatever type, concerning the hereditary characteristics of an individual or concerning the pattern of inheritance of such characteristics within a related group of individuals." (Council of Europe and Committee of Ministers 1997)

Recent guidelines from Australia for the disclosure of genetic information by health professionals also take a broad view of this information, noting that it can come from a wide range of sources, including family history, and can confirm a particular condition or predict the likelihood of carrying a mutated gene (Government of Australia 2009).

\section{Consequences for broad and narrow conceptions of genetic information}

The use of a broad or narrow definition of genetic information for the purposes of encouraging intrafamilial communication can have important consequences for family members and patients alike. For family members, the consequences of a narrow definition based solely on inheritable characteristics ascertained through laboratory testing means that other information - risk prediction scores or tumor pathology results indicative of hereditary cancer-would not be information that patients are encouraged to share with their families. This is important because other information such as family history of breast cancer is often what prompts physicians to initially suggest genetic testing, cascade screening, or to utilize a risk assessment model (Acheson et al. 2000; Panchal et al. 2008). Thus if patients are not encouraged to disclose this information to their families or made aware of the benefits, family members might not gain access to testing.

Adopting a broader definition of genetic information that would include risk assessment scores, tumor pathology results, and family history could, however, come at the 
expense of the patient's own interests. Despite the presence of laws designed to prevent it, concerns about the possibility of misuse of genetic information or family history in decisions regarding employment or access to insurance remain widespread (Schmitz and Wiesing 2006; Lucassen et al. 2006). If patients were aware of the expectation of informing their relatives of a wider range of medical test results and information, they may hesitate to seek testing for a number of reasons, including concern for the consequences of having the information as part of their own medical file. Indeed, the concern is not only about how this information will be used, but also about how family members will react, how they will view the patient, or how the patient views him or herself in relation to others in the family (Nycum et al. 2009b; Gilbar 2007).

\section{Points to consider: genetic information}

1. Genetic information is information that provides insight into a person's genetic makeup and risk for particular diseases and disorders. It incorporates a wide variety of medical information, including:

(a) Laboratory analyses including DNA and non-DNA-based testing suggestive of heritable conditions

(b) Information from risk assessment models

(c) Family medical history

(d) Genetic testing of other family members

2. A patient's risk for developing cancer and the basis for that risk should be included as part of the genetic information that is conveyed to family members, as it is key to fully understanding familial risk. Patients must be provided with information that explains what their risk means and which dispels any misconceptions about an increase or decrease in risk.

3. When considering what constitutes genetic information that patients should be encouraged to share with their families, attention should be paid to balancing the benefits a broader definition would bring to families with the cost it would incur on patients.

Intrafamilial disclosure of genetic information as a personal responsibility

In our previous work on this subject (Nycum et al. 2009a), the focus was whether there is conceivably a legal obligation for patients to communicate genetic information to family members, especially as pertains to Canadian law. Here, our focus turns to the potential for personal responsibility. The distinction between legal and personal is one of flexibility, jurisdiction, and oversight. The balancing of these factors suggests that a legal obligation would be ill-advised, and in any event, a legal obligation has yet to be established in any jurisdiction. Thus, a personal responsibility for patients to disclose genetic information to family is preferable and more realistic.

\section{A personal responsibility to disclose genetic information}

A personal responsibility to disclose genetic information is more permissive in describing what we expect to happen in family relationships, as opposed to a legal obligation, which is more about what we require. In this instance, it permits a patient to decide what, to whom, when, and how to disclose information that could have an impact on the health of a family member, as well as on the family member's relationship with the patient. The familial context of each patient is different (Wiseman et al. 2010), and a personal responsibility recognizes this.

This responsibility has adherents in national and international guidelines and policies that promote patient disclosure of genetic risk to their families. Although these are often not detailed, they are a starting point for discussion.

In Germany, a personal responsibility to communicate genetic risk is explicit. "A moral obligation of family members to share their knowledge of their genetic makeup can be seen, as well as a moral obligation of partners to inform each other of their medical genetic problems, insofar as the latter concern children they may have in common" (German Society of Human Genetics 1998). France also takes a more explicit view of the obligation of patients. The National Consultative Ethics Committee for Health and Life Sciences makes clear that the patient has the moral responsibility (though not the legal) to disclose pertinent information to those who could benefit (France National Consultative Ethics Committee for Health and Life Sciences (CCNE) 2003).

In the UK, the General Medical Council recognizes that most patients will share genetic information with relatives if properly advised of the health implications of the information (General Medical Council 2009). The Nuffield Council on Bioethics is clear that patients "acting responsibly would normally wish to communicate important genetic information to other family members who may have an interest in that information, and... that the primary responsibility for communicating genetic information to a family member or other third party lies with the [patient] and not with the doctor who may, however, do this at the request of the person concerned" (Nuffield Council on Bioethics 1993). This statement places responsibility for disclosure solely with the patient, though it does not provide further direction as to how and when patients should do so. Finally, the Joint Committee on Medical Genetics recently released guidance on consent in genetic practice, emphasizing the importance that genetic information might hold for family members and recognizing the patient as a potential source of the disclosure (Royal College of Physicians et al. 2011).

Other guidance implies a responsibility for patients to inform family of risk. The American Society of Human Genetics states that "[a]t a minimum, the health care 
professional should be obliged to inform the patient of the implications of his/her genetic test results and potential risks to family members" (American Society of Human Genetics and Social Issues Subcommittee on Familial Disclosure 1998). This policy in effect places responsibility on patients to inform family members of risk, but does explicitly advise health care professionals to direct patients to do so.

All of this guidance recognizes the importance of family, rather than others such as physicians, as being the ones to share genetic information with other family members. There is evidence that in the majority of cases, patients will eventually share their genetic status with relevant family members (Nuffield Council on Bioethics 1993; Hallowell et al. 2003; Julian-Reynier et al. 2000; Bradbury et al. 2007; Cheung et al. 2010). This might be based on the closeness of the relationship or a duty felt towards others, rather than any explicit personal responsibility (Hallowell et al. 2003). Although disclosure might not be immediate, the fact that it usually happens (eventually) should be comforting to those who worry about whether family will be informed of this important information.

Of course, in a voluntary system of personal responsibility, not all patients will choose to disclose - such is the nature of this system. However, with strong support for voluntary disclosure, patients can be reassured and educated in how to share this information.

\section{Disclosure to children}

Special consideration must be given to whether a personal responsibility to disclose genetic information to family extends to young children. Informing children about genetic risks is something that many parents struggle with. Issues with guilt (Clarke et al. 2008) and stress in the relationship can determine whether, when and how a parent tells his or her children about a genetic risk. The decision involves the balancing of many factors such as age and ability to comprehend. Other factors, such as severity of the disease and availability of prophylactic measures, are specific to a particular disease. There are no clear rules on how and when to inform children of genetic risk, although informing them prior to an age when they understand what the information means and/or can be proactive is discouraged (Mackenzie et al. 2009), indicated as well by parents being advised to delay involvement of children in the genetic counseling process (Bradbury et al. 2007).

It is generally recommended, at least at the present time, that children should not be tested for adult onset genetic diseases until they are able to exercise their autonomy (American Society of Human Genetics and American College of Medical Genetics 1995; Public and Professional Policy Committee of the European Society of Human Genetics 2009; Mackenzie et al. 2009; American Academy of Pediatrics and Committee on
Bioethics 2001; Royal College of Physicians et al. 2011). However, there is no such limitation on informing children that they might be at genetic risk (Mackenzie et al. 2009). Some studies have shown that parents will inform young children (e.g., below age 13) regardless of their ability to truly understand and before monitoring, genetic testing, or prophylactic surgeries such as mastectomies or oophorectomies (surgical removal of the ovaries) are recommended (Mackenzie et al. 2009; McGivern et al. 2004).

There are risks, such as emotional harm, that accompany in telling a child of genetic risk at an age when they are too young to fully comprehend its meaning or participate in monitoring, testing, and screening programs. However, delaying disclosure could lead to a feeling of dishonesty on the part of the parent (Bradbury et al. 2009; Cappelli et al. 2005; American Academy of Pediatrics and Committee on Bioethics 2001), and the child might still be able to determine through other methods (non-verbal cues, overheard fragments of discussion, knowledge of ongoing medical treatment) that something is wrong and they are not being told. An additional consideration supporting disclosure is that knowledge of risk at a young age can also help reduce behaviors that increase risk (Clarke et al. 2008), although the evidence of this is not conclusive (Bradbury et al. 2009).

There is no established framework as to when and how parents should inform children about their genetic risk for hereditary breast and ovarian cancer and whether children should be part of the counseling process. The parent's need to inform the child and the child's ability to understand are considerations. Although waiting until a child is of an age when monitoring and screening are recommended has been advised (early adulthood), disclosing when they are able to understand and adopt risk-reducing behaviors (such as adolescence) might provide some level of benefit. In addition, parents might need the guidance of health professionals - who are often better equipped to understand the types of information that should be disclosed at a given age, as well as the best way of going about it-when disclosing this information to children (McBride et al. 2010).

\section{The right not to know}

Although there should be a personal responsibility for patients to inform family members of genetic risk, there might be circumstances when those family members legitimately do not want to know: this is their purported right not to know. Traditionally, the right not to know one's genetic status has been considered in the context of the physicianpatient relationship. The existence of this right among family members, however, has been and continues to be debated (Gilbar 2007). 
Recognized by international ethical and legal instruments, including the UNESCO Universal Declaration on the Human Genome and Human Rights (UNESCO 1997) and the European Convention on Human Rights and Biomedicine (Council of Europe 1997), the right not to know dictates that "everyone is entitled to know any information collected about his or her health. However, the wishes of individuals not to be so informed shall be observed" (Council of Europe 1997). In opposition to a presumption of this right, some have proposed that the right is activated through explicit choice (Andorno 2004), meaning that a family member must state their desire not to know before the patient is obligated to not inform them. Potentially, trying to discern preferences without guidance from the family member can create a dilemma for the patient: by not disclosing the patient might be observing this right, but they would also fail to fulfill the "need for the provision of information sufficient to allow people to make meaningful choices" (Laurie 1999). In addition, by trying to determine a relative's wishes, the patient might have to disclose the existence of a potential risk (e.g., by asking "do you want to know your genetic risk?") so that the purpose of the right not to know is defeated (Laurie 1999).

For these reasons, the personal responsibility to communicate genetic risk information should be tempered by a more informal observance of the right not to know. This would permit a well-grounded decision not to inform without an explicit refusal by a family member, if the patient reasonably believes that the family member would not want to receive the information: "patients can reach a decision after a careful process based on the sharing of thoughts, beliefs, and desires in the family" (Gilbar 2005). This is not a perfect solution, as patients will not always know the wishes of others in their family and poor intrafamilial relationships could create additional difficulties. However, considering the complexity raised above concerning the deciphering of a family member's wishes without explicit statements, granting patients' discretion to disclose or not or to gain more information from family members regarding their wishes is perhaps the most realistic solution.

Points to consider: personal responsibility to communicate genetic risk to family members

1. Disclosure of genetic risk by patients to their families should be a personal and voluntary obligation, as the practical implication of a personal responsibility is to create an atmosphere that encourages and promotes voluntary disclosure.

2. The decision to disclose should be made by the patient, following guidance from a health professional when needed.

3. Patients should be informed of the familial nature of genetic information and their obligation to communicate this information to family members as part of pre- and posttest genetic counseling.

4. Children, when sufficiently mature, should not be automatically excluded from parents' efforts to inform family members of genetic risk, as they have at least as much interest in the information as other members of the family. Genetic risk information can be both valid and useful for children to know and can permit them to incorporate behaviors that lessen risks. However, this knowledge can also have a negative impact, such as emotional distress from the realization that the risk is lifelong, thus disclosure to children should be done in a manner sensitive to their maturity and needs.

5. The patient is in the best position to anticipate the wishes of family members, and members' right not to know should be considered as part of the decision to disclose genetic risk information.

What is the role of health professionals in the disclosure of genetic risk information within the family?

A patient seeking genetic testing or information about genetic risks will likely communicate with a number of health professionals. A personal physician first approached about the issue might refer the patient to a genetic specialist, who might also incorporate the services of a genetic counsellor. What role do any or all of these professionals have in the communication of genetic risk information to a patient's family?

The duty to protect patient privacy and maintain confidentiality has been a cornerstone of the physician-patient relationship since the advent of the Hippocratic Oath (Metcalfe et al. 2008). Based on the underlying values of individual autonomy, trust, and respect for confidentiality, today's guidelines governing the relationship between patients and health care professionals dictate that information obtained during the course of the relationship will not be disclosed to third parties unless expressly authorized by the patient or as required by law. Although much has been made of the potential ability or duty (ethical or legal) of health professionals to disclose genetic information without the permission of the patient (Lucassen and Parker 2010), for the purposes of this document, we are referring to health professional disclosure or participation in the disclosure process with the consent of the patient. The policy positions and literature analyzed below often address both contexts together.

Such a function of physicians and other health professionals has the support of professional associations (Canadian Nurses Association 2008; Canadian Medical Association 2004; Canadian Association of Genetic Counsellors 2006). The American Medical Association (AMA) proposes that patients and physicians discuss, prior to testing, the necessity of disclosing test outcomes to family members (American Medical Association Council on Ethical and Judicial Affairs 2008; Taub et al. 2004). The AMA further emphasizes that the role of the physician is to educate the patient about the risks of not communicating and facilitating communication with family members where necessary. 
The Nuffield Council on Bioethics in the UK also advocates a role for health professionals apart from informing family members without the consent of a patient:

"We recommend that... health professionals should seek to persuade individuals, if persuasion should be necessary, to allow the disclosure of relevant genetic information to other family members. They should also seek to ensure that treatment, counseling and other appropriate support are made available to those to whom such unsought information is disclosed." (Nuffield Council on Bioethics 1993)

In 2006, the council further raised the possibility of a system that "assumes that relevant information will be disclosed to all affected parties unless there is good reason (such as risk of harm) for it to be withheld" (Nuffield Council on Bioethics 2006).

The Joint Committee on Medical Genetics further strengthens the British position on intrafamilial communication by advocating for a discussion of intrafamilial disclosure during the consent process to ensure patients have an understanding of the potential implications of genetic information for their families (Royal College of Physicians et al. 2011). It also notes that "[t]he assumption that confidentiality is always paramount is as inappropriate as the assumption that disclosure is always permissible, and the decision will need to be tailored to the individual circumstances of the case," thereby raising the potential for familial disclosure without the consent of the patient (Royal College of Physicians et al. 2011). Likewise, the General Medical Council foresees instances when patients will not disclose and states that physicians may balance the duty to care for the patient with the duty to protect third parties from harm, implying that if the harm is serious enough, confidentiality may be breached (General Medical Council 2009).

Australia permits disclosure to family without the consent of the patient in certain circumstances and provides detailed guidelines to this effect (Government of Australia 2009). Although these guidelines permit such disclosure, medical practitioners should encourage patients to disclose to families themselves or to consent to the practitioner's disclosure. Failing this, practitioners can proceed with disclosure without consent in limited circumstances.

Others have advocated for a different approach in an effort to promote communication of genetic information within families (Doukas and Berg 2001). For example, the family covenant, a health care agreement among patients within a family and their family physician, is one model proposed to lessen the absolute confidentiality of genetic information between physician and patient (Doukas and Berg 2001). In this model, the family as a whole is the unit of care and members negotiate the obligations of physician and family members among each other at the outset. Thus, if a patient in the covenant obtains medical information, such as genetic test results, that has relevance for the physical health of other family members, the covenant may foresee an obligation by the patient to share this information. The consequences if the patient repudiates the covenant and refuses to disclose are problematic: the physician would still likely be ethically and legally required to maintain confidentiality unless, in the circumstances of genetic testing, the jurisdiction permitted disclosure to third parties who may be at risk of harm. However, these covenants would at least permit families and physicians to have discussions pretesting about its implications and the potential for family members to be tested for a genetic predisposition.

In sum, health professionals still have a significant role to play in facilitating intrafamilial communication of potential genetic risk for hereditary breast and ovarian cancer, whether or not they otherwise have the legal or ethical obligation to directly inform patients' families of this information. For one, they can inform patients before and after testing about the potential impact the results could have on family (Cheung et al. 2010) and the potential that family members might not want to know (an exercise of the right not to know). They can also offer to aid patients with their communication (Nycum et al. 2009b; Lacroix et al. 2008), such as being present when the patient discloses to answer any questions the family member(s) might have. This could be especially helpful to assist patients and their families understand what the results really mean to the family, rather than relying on preconceptions held by the family which might be inaccurate (Lacroix et al. 2008). By providing information and guidance, health professionals might also be persuasive in encouraging patients to inform extended family members, rather than just their immediate families, as patients do not always have the urge to do so (Werner-Lin 2007).

While frontline delivery health care professionals have an essential role to play in leading such discussions, at present, they may be ill equipped to take on such a role (McGivern et al. 2004). For example, nearly half of all nurses and one third of physicians practicing in Canada reported in 2005 having no formal training in genetics (Bottorff et al. 2005). The ability of health care professionals to communicate risk and patients' ability to understand risk are factors that have been shown to influence intrafamilial communication of breast cancer risk among families (Plon et al. 2011). It can be challenging for health care professionals to communicate risk information, and misunderstandings about genetic risk for breast cancer have been reported (Cheung et al. 2010) and can be amplified when sharing the information with relatives (Ahmed et al. 2012). Factors such as age, gender, culture, and education have been shown to influence perception and ability to comprehend risk (Vos et al. 2011). Given the rapidly evolving nature of genetic risk 
information and the complexity of the subject, it is clear that many health care professionals will require additional training and support in order to facilitate discussions with their patients about genetic risk and genetic testing (Sussner et al. 2011).

Points to consider: role of health professionals

1. Health professionals have a considerable role to play in promoting intrafamilial communication and can:

(a) Prior to testing, inform patients of the risk indicated by genetic information, both for themselves and for family members

(b) Offer to aid patients in communicating genetic risk information to the family or refer them to someone who can, if a patient so requests

(c) Attempt to persuade patients who are uncomfortable with disclosing genetic risk information that such disclosures might be necessary, even to relatives with whom the patient does not have a close relationship

2. Guidelines and training programs should be developed to assist health professionals in discussing the communication needs of patients.

3. Health professionals may decide, depending on relevant legal and ethical considerations, to override a patient's objection to informing family members and inform them him or herself. However, both the professional and patient are best served by the patient informing his or her own family members, or at very least authorizing a health professional to do so.

\section{Conclusion}

Knowledge of one's risk and genetic information is an important step towards early detection or prevention of hereditary breast cancer. Information about risk can come from family history, from a family member who has been tested for a genetic mutation, or from use of a risk prediction model. Although the only way to know for sure that one has the same mutation is to be tested or diagnosed, often it is these other various sources of information that lead a person to be tested in the first place. It has thus been questioned whether a person who knows or strongly suspects they carry a mutation must share this information with others in their family.

In brief, we have discussed a number of key considerations that must be addressed when dealing with intrafamilial communication. Based on a review of the relevant literature and of laws and guidelines from the USA, Canada, the UK, Australia, and various medical organizations, we have highlighted important points to consider when determining how to address intrafamilial communication of genetic risk in the clinical setting. To summarize, any duty on patients to disclose genetic risk information to family members should be personal, not legal, and should apply to a broad spectrum of family members and information. Health professionals can have an important role in conveying information to the patient, but the final decision of what, how, to whom, and when to disclose should remain with the patient to the extent possible. Genetic risk information is sensitive medical information and implicates both patients and others in their family. Strong reasons have not yet been provided to completely deprive patients of their traditional control over what happens to this information.

This represents only an initial step towards fostering better communication within families. Indeed, the lack of consensus about what constitutes genetic information or the "genetic" family, or even discussion of the issue of intrafamilial communication, in various jurisdictions and organizations that otherwise have laws, regulations, or guidelines for genetic testing and disclosure of results speaks to both the novelty and complexity of this issue. We do not claim to have comprehensively analyzed intrafamilial communication. Rather, we suggest that additional research is needed to determine the best methods for encouraging this communication and motivations for disclosing or not and provide points to consider when developing a solution, considering the complexity of human relationships and the probabilistic nature of genetic information. With the promise of continuing advances in genetic discoveries and medical treatment, the matter of intrafamilial disclosure of risk for hereditary breast cancer is here to stay.

Acknowledgments The authors would like to acknowledge the assistance and financial support of the Canadian Breast Cancer Research Alliance and the Canadian Institutes of Health Research Team of Prediction and Communication of Familial Risks of Breast Cancer.

Conflict of interest The authors declare that they have no conflict of interest.

Open Access This article is distributed under the terms of the Creative Commons Attribution License which permits any use, distribution, and reproduction in any medium, provided the original author(s) and the source are credited.

\section{References}

Acheson LS, Wiesner GL, Zyzanski SJ, Goodwin MA, Stange KC (2000) Family history-taking in community family practice: implications for genetic screening. Genet Med 2(3):180-185

Ahmed H, Naik G, Willoughby H, Edwards AG (2012) Communicating risk. BMJ 344:e3996

American Academy of Pediatrics, Committee on Bioethics (2001) Ethical issues with genetic testing in pediatrics. Pediatrics 107 (6):1451-1455

American Medical Association Council on Ethical and Judicial Affairs (2008) Code of Medical Ethics of the American Medical Association, Opinion E-2.131, disclosure of familial risk in genetic testing. American Medical Association, Chicago

American Society of Clinical Oncology (2003) American Society of Clinical Oncology Policy Statement update: genetic testing for cancer susceptibility. J Clin Oncol 21(12):1-10 
American Society of Human Genetics (2000) ASHG Family Medical History and Privacy Advisory. http://www.ashg.org/pdf/policy/ ASHG_PS March2000_v2.pdf. Accessed 23 Jan 2012

American Society of Human Genetics and American College of Medical Genetics (1995) Points to consider: ethical, legal, and psychological implications of genetic testing in children and adolescents. Am J Hum Genet 57:1233-1241

American Society of Human Genetics, Social Issues Subcommittee on Familial Disclosure (1998) Professional disclosure of familial genetic information. Am J Hum Genet 62(2):474-483

Andorno R (2004) The right not to know: an autonomy based approach. J Med Ethics 30(5):435-439

Antoniou AC, Cunningham AP, Peto J, Evans DG, Lalloo F, Narod SA, Risch HA, Eyfjord JE, Hopper JL, Southey MC, Olsson H, Johannsson O, Borg A, Pasini B, Radice P, Manoukian S, Eccles DM, Tang N, Olah E, Anton-Culver H, Warner E, Lubinski J, Gronwald J, Gorski B, Tryggvadottir L, Syrjakoski K, Kallioniemi OP, Eerola H, Nevanlinna H, Pharoah PD, Easton DF (2008) The BOADICEA model of genetic susceptibility to breast and ovarian cancers: updates and extensions. $\mathrm{Br} \mathrm{J}$ Cancer 98(8):1457-1466

Bottorff JL, Blaine S, Carroll JC, Esplen MJ, Evans J, Nicolson Klimek ML, Meschino W, Ritvo P (2005) The educational needs and professional roles of Canadian physicians and nurses regarding genetic testing and adult onset hereditary disease. Community Genet 8(2):80-87

Bradbury AR, Dignam JJ, Ibe CN, Auh SL, Hlubocky FJ, Cummings SA, White M, Olopade OI, Daugherty CK (2007) How often do BRCA mutation carriers tell their young children of the family's risk for cancer? A study of parental disclosure of BRCA mutations to minors and young adults. J Clin Oncol 25(24):3705-3711

Bradbury AR, Patrick-Miller L, Pawlowski K, Ibe CN, Cummings SA, Hlubocky F, Olopade OI, Daugherty CK (2009) Learning of your parent's BRCA mutation during adolescence or early adulthood: a study of offspring experiences. Psychooncology 18(2):200-208

Canadian Association of Genetic Counsellors (2006) Code of Ethics for Canadian Genetic Counsellors Oakville, ON

Canadian Medical Association (1999) Listening to our patient's concerns: Comments on Bill C-54 (Personal Information Protection and Electronic Documents Act). Ottawa

Canadian Medical Association (2004) CMA code of ethics. Canadian Medical Association, Ottawa

Canadian Nurses Association (2008) Code of ethics for registered nurses. Canadian Nurses Association, Ottawa

Cappelli M, Verma S, Korneluk Y, Hunter A, Tomiak E, Allanson J, DeGrasse C, Corsini L, Humphreys L (2005) Psychological and genetic counseling implications for adolescent daughters of mothers with breast cancer. Clin Genet 67(6):481-491

Carroll JC, Cremin C, Allanson J, Blaine SM, Dorman H, Gibbons CA, Grimshaw J, Honeywell C, Meschino WS, Permaul J, Wilson BJ (2008) Hereditary breast and ovarian cancers. Can Fam Physician 54(12):1691-1692

Cheung EL, Olson AD, Tina MY, Han PZ, Beattie MS (2010) Communication of BRCA results and family testing in 1,103 high-risk women. Cancer Epid Biomark Prev 19(9):2211-2219

Claes E, Evers-Kiebooms G, Boogaerts A, Decruyenaere M, Denayer L, Legius E (2003) Communication with close and distant relatives in the context of genetic testing for hereditary breast and ovarian cancer in cancer patients. Am J Med Genet A 116(1):11-19

Clarke S, Butler K, Esplen MJ (2008) The phases of disclosing BRCA1/2 genetic information to offspring. Psychooncology 17 (8):797-803

Council of Europe (1997) Convention on Human Rights and Biomedicine CETS No. 164. Oviedo
Council of Europe, Committee of Ministers (1997) Recommendation R (97)5 on the Protection of Medical Data. Strasbourg

Doukas DJ, Berg JW (2001) The family covenant and genetic testing. Am J Bioeth 1(3):3-10

European Commission: The Independent Expert Group (2004) Ethical, legal and social aspects of genetic testing: research, development and clinical applications. Brussels

Forrest LE, Delatycki MB, Skene L, Aitken M (2007) Communicating genetic information in families - a review of guidelines and position papers. Eur J Hum Genet 15(6):612-618

Foster C, Eeles R, Ardern-Jones A, Moynihan C, Watson M (2004) Juggling roles and expectations: dilemmas faced by women talking to relatives about cancer and genetic testing. Psychol Heal 19 (4):439-455

France National Consultative Ethics Committee for Health and Life Sciences (CCNE) (2003) Opinion no 76 regarding the obligation to disclose genetic information of concern to the family on the event of medical necessity. Paris.

General Medical Council (2009) Confidentiality. General Medical Council, London

Genetic Information Privacy Act (2009) 410 I.L.C.S. $513 \S 10$

German Society of Human Genetics (1998) Position Paper of the German Society of Human Genetics. German Society of Human Genetics, Munich

Gilbar R (2005) The status of the family in law and bioethics. Ashgate, Burlington

Gilbar R (2007) Communicating genetic information in the family: the familial relationship as the forgotten factor. J Med Ethics 33 (7):390-393

Government of Australia (1998) Australia Genetic Privacy and NonDiscrimination Bill

Government of Australia (2009) Use and disclosure of genetic information to a patient's genetic relatives under section 95AA of the Privacy Act of 1988 (Ch): guidelines for health practitioners in the private sector.

Guttmacher AE, Collins FS, Carmona RH (2004) The family historymore important than ever. N Engl J Med 351(22):2333-2336

Hallowell N, Foster C, Eeles R, Ardern-Jones A, Murday V, Watson M (2003) Balancing autonomy and responsibility: the ethics of generating and disclosing genetic information. J Med Ethics 29 (2):74-79, discussion 80-73

Hallowell N, Ardern-Jones A, Eeles R, Foster C, Lucassen A, Moynihan C, Watson M (2005) Communication about genetic testing in families of male BRCA1/2 carriers and non-carriers: patterns, priorities and problems. Clin Genet 67(6):492-502

Human Genetics Commission (2002) Inside information: balancing interests in the use of personal genetic data. Human Genetics Commission, London

Jacobi CE, de Bock GH, Siegerink B, van Asperen CJ (2009) Differences and similarities in breast cancer risk assessment models in clinical practice: which model to choose? Breast Cancer Res Treat 115(2):381-390

Julian-Reynier C, Eisinger F, Chabal F, Lasset C, Nogues C, StoppaLyonnet D, Vennin P, Sobol H (2000) Disclosure to the family of breast/ovarian cancer genetic test results: patient's willingness and associated factors. Am J Med Genet 94(1):13-18

Kissane DW, Bylund CL, Banerjee SC, Bialer PA, Levin TT, Maloney EK, D'Agostino TA (2012) Communication skills training for oncology professionals. J Clin Oncol 30(11):1242-1247

Koehly LM, Peters JA, Kenen R, Hoskins LM, Ersig AL, Kuhn NR, Loud JT, Greene MH (2009) Characteristics of health information gatherers, disseminators, and blockers within families at risk of hereditary cancer: implications for family health communication interventions. Am J Public Health 99(12):2203-2209

Lacroix M, Nycum G, Godard B, Knoppers BM (2008) Should physicians warn patients' relatives of genetic risks? CMAJ 178(5):593-595 
Laurie GT (1999) In defence of ignorance: genetic information and the right not to know. Eur J Health Law 6(2):119-132

Laurie G (2002) Genetic privacy: a challenge to medico-legal norms. Cambridge University Press, Cambridge

Lucassen A, Parker M (2010) Confidentiality and sharing genetic information with relatives. Lancet 375(9725):1507-1509

Lucassen A, Parker M, Wheeler R (2006) Implications of data protection legislation for family history. BMJ 332(7536):299-301

MacDonald D, Sarna L, Weitzel J, Ferrell B (2010) Women's perceptions of the personal and family impact of genetic cancer risk assessment: focus group findings. J Genet Couns 19(2):148-160

Mackenzie A, Patrick-Miller L, Bradbury AR (2009) Controversies in communication of genetic risk for hereditary breast cancer. Breast J 15(Suppl 1):S25-S32

McBride CM, Koehly LM, Sanderson SC, Kaphingst KA (2010) The behavioral response to personalized genetic information: will genetic risk profiles motivate individuals and families to choose more healthful behaviors? Annu Rev Public Health 31:89-103

McGivern B, Everett J, Yager GG, Baumiller RC, Hafertepen A, Saal HM (2004) Family communication about positive BRCA1 and BRCA2 genetic test results. Genet Med 6(6):503-509

Meiser B, Gleeson M, Watts K, Peate M, Zilliacus E, Barlow-Stewart K, Saunders C, Mitchell G, Kirk J (2012) Getting to the point: what women newly diagnosed with breast cancer want to know about treatment-focused genetic testing. Oncol Nurs Forum 39(2): E101-E111

Metcalfe A, Coad J, Plumridge GM, Gill P, Farndon P (2008) Family communication between children and their parents about inherited genetic conditions: a meta-synthesis of the research. Eur J Hum Genet 16(10):1193-1200

Meyer P, Landgraf K, Hogel B, Eiermann W, Ataseven B (2012) BRCA2 mutations and triple-negative breast cancer. PLoS One 7(5):e38361

Nuffield Council on Bioethics (1993) Genetic Screening: Ethical Issues. Nuffield Council on Bioethics, London

Nuffield Council on Bioethics (2006) Genetic Screening: a Supplement to the 1993 Report by the Nuffield Council on Bioethics. Nuffield Council on Bioethics, London

Nycum G, Avard D, Knoppers B (2009a) Intra-familial obligations to communicate genetic risk information: what foundations? What forms? McGill J Law Health 3:21-48

Nycum G, Avard D, Knoppers BM (2009b) Factors influencing intrafamilial communication of hereditary breast and ovarian cancer genetic information. Eur J Hum Genet 17(7):872-880

O'Neill O (1997) Genetic information and insurance: some ethical issues. Philos Trans R Soc London Series B Biol Sci 352(1357):1087-1093

Panchal SM, Ennis M, Canon S, Bordeleau LJ (2008) Selecting a BRCA risk assessment model for use in a familial cancer clinic. BMC Med Genet 9:116

Patty A (2012) Gene test results to be passed on without consent. Sydney Morning Herald, May 30, 2012

Pelletier S, Dorval M (2004) Predictive genetic testing raises new professional challenges for psychologists. Can Psychol Psychol Can 45(1): 16
Peshkin BN, Alabek ML, Isaacs C (2010) BRCA1/2 mutations and triple negative breast cancers. Breast Dis 32(1-2):2533

Peters J, Kenen R, Hoskins L, Koehly L, Graubard B, Loud J, Greene M (2011) Unpacking the blockers: understanding perceptions and social constraints of Health Communication in Hereditary Breast Ovarian Cancer (HBOC) susceptibility families. J Genet Couns 20(5):450-464

Plon SE, Cooper HP, Parks B, Dhar SU, Kelly PA, Weinberg AD, Staggs S, Wang T, Hilsenbeck S (2011) Genetic testing and cancer risk management recommendations by physicians for at-risk relatives. Genet Med 13(2):148

Public and Professional Policy Committee of the European Society of Human Genetics (2009) Genetic testing in asymptomatic minors: recommendations of the European Society of Human Genetics. Eur J Hum Genet 17(6):720-721

Royal College of Physicians, Royal College of Pathologists, British Society for Human Genetics (2011) consent and confidentiality in clinical genetic practice: Guidance on genetic testing and sharing genetic information. 2nd edn. Report of the Joint Committee on Medical Genetics, London

Schmitz D, Wiesing U (2006) Just a family medical history? BMJ 332 (7536):297-299

Sussner KM, Jandorf L, Valdimarsdottir HB (2011) Educational needs about cancer family history and genetic counseling for cancer risk among frontline healthcare clinicians in New York City. Genet Med 13(9):785

Taub S, Morin K, Spillman MA, Sade RM, Riddick FA (2004) Managing familial risk in genetic testing. Genet Test 8(3):356-359

U.S. Bill H.R. 493 Genetic Information Nondiscrimination Act of 2008 (110th Cong.) 2008 (enacted)

United Nations Educational Scientific and Cultural Organization (UNESCO) (1997) Universal declaration on the human genome and human rights. Paris

United Nations Educational Scientific and Cultural Organization (UNESCO) (2003) International declaration on human genetic data. Paris.

Vos J, Menko F, Jansen AM, van Asperen CJ, Stiggelbout AM, Tibben A (2011) A whisper-game perspective on the family communication of DNA-test results: a retrospective study on the communication process of BRCA1/2-test results between proband and relatives. Familial Cancer: $1-10$

Watson MS, Greene CL (2001) Points to consider in preventing unfair discrimination based on genetic disease risk: a position statement of the American College of Medical Genetics. Genet Med 3 (6):436-437

Watters v. White (2012). QCCA, vol 257. Quebec Court of Appeal

Werner-Lin AV (2007) Danger zones: risk perceptions of young women from families with hereditary breast and ovarian cancer. Fam Process 46(3):335-349

Wiseman M, Dancyger C, Michie S (2010) Communicating genetic risk information within families: a review. Familial Cancer 9 (4):691-703 